\title{
Performance Evaluation of Strengthening Recycled Coarse Aggregate in Cement Stabilized Mixture Base Layer of Pavement
}

\author{
Junhui Zhang $(\mathbb{D}$, Cheng Li, Le Ding $(\mathbb{D}$, and Henggang Zhao $\mathbb{i}$ \\ National Engineering Laboratory of Highway Maintenance Technology, Changsha University of Science \& Technology, Changsha, \\ Hunan 410114, China \\ Correspondence should be addressed to Junhui Zhang; zjhseu@csust.edu.cn
}

Received 18 August 2020; Revised 9 December 2020; Accepted 15 December 2020; Published 28 December 2020

Academic Editor: Linglin Li

Copyright ( 92020 Junhui Zhang et al. This is an open access article distributed under the Creative Commons Attribution License, which permits unrestricted use, distribution, and reproduction in any medium, provided the original work is properly cited.

This paper attempts to study the effect of different strengthening methods on recycled coarse aggregate (RCA) reprocessed from construction and demolition (C\&D) waste. And it aims to obtain the optimal RCA content in cement stabilized recycled mixture (CSRM) applied in the base layer of pavement. Firstly, three strengthening methods were used to strengthen the RCA. It was revealed that the sodium silicate solution is the best method in a strengthening concentration of $8 \%$ and strengthening for five hours. Then, the mechanical experiments under two cement dosages, including unconfined compressive strength, splitting strength, and compressive rebound modulus tests, were carried out. In each cement dosage, five different RCA contents $(0 \%, 25 \%$, $50 \%, 75 \%$, and $100 \%$ ) were considered. It was found that, at $5 \%$ of cement dosage, the strength of CSRM satisfied the requirements of the base layer of the expressway under heavy traffic load. In the case of $4 \%$ of cement dosage, the strength of CSRM which was beyond $50 \%$ of RCA content was failed to meet specification requirements. For the failed cases, by strengthening RCA in the best method obtained before, $7 \mathrm{~d}$ unconfined strength and crushing value of the CSRM with 50\% RCA content could meet the requirements of the subbase of expressways and first-class highways in China; the $75 \%$ of the mixture meets the requirements of the second-class highways and below.

\section{Introduction}

The rapid development of China's urbanization has resulted in massive generation of $\mathrm{C} \& \mathrm{D}$ waste, and it represents more than $30 \%$ of the world's municipal solid waste, 2 billion tons in 2019 [1]. After separating, screening, and removal of impurities, converting C\&D waste into RCA and then applying it into road engineering have become a hot issue at present. Many research studies show that C\&D waste has been widely utilized as materials of pavement base $[2,3]$ and subgrade fillers [4, 5]. In addition, by the end of 2030, 47,000 kilometers of highways and 100,000 kilometers of national highways will be built in China [6]. The increasing demands of construction in highway will lead to significant increasing depletion of natural aggregate sources. Due to the strict restrictions on exploitation of natural aggregates, there is a growing gap between the demand and supply capacity of road sources materials. Utilization of RCA into the pavement construction industry contributes to improving the efficiency and sustainability by conservation of raw materials and reduction of the landfilled C\&D waste amount and greenhouse gas emission [7-10].

Characterization studies of RCA have been conducted in recent years. Compared with natural coarse aggregate, RCA has higher crushing index, larger water absorption rate, and lower apparent density $[11,12]$. Microexperiments were carried out to analyze the reasons for these differences $[13,14]$. Some studies also have shown that the cement kilns, fly ash, etc. considerably help to improve its performance $[15,16]$. At the same time, in order to make better use of RCA, various enhancement methods have been proposed to improve the performance of RCA, including mechanical device [17], nanosilica and bacteria [18], waste basalt powder [19], and microbial carbonate precipitation treatment [20]. However, there were no experiments carried out to establish the relationship between the above strengthening methods 
and the mechanical properties of CSRM under the condition of different RCA contents and cement dosages.

At present, many scholars have carried out researches on the strength, stiffness, crack resistance, and shrinkage properties of CSRM by utilizing RCA as materials in the base layer of highway [21-23]. Researchers have found that, with the increase of RCA content, the mechanical properties will deteriorate [24-26]. Under the same cement dosage, after mixing with RCA, the compressive strength of CSRM will be reduced by $12 \%$ to $25 \%[27,28]$. Butler [29] even concluded that it will be reduced by $30 \%$. At the same time, the RCA will also have a certain impact on the flexural strength and unit wear loss of CSRM [11]. Therefore, the natural coarse aggregate can be only partially replaced by RCA to meet the requirements of the pavement base. Mills-Beale suggested that the RCA content should not exceed 75\% [30]. Under a single cement dosage, Poon and Chan [31] and Azam and Cameron [32] have carried out researches on the performance of RCA as a base or subbase layer of granular materials. Resilient modulus is also a mechanical performance index that can be studied $[33,34]$. Li et al. [35] concluded that the RCA content should not exceed $75 \%$ from the perspective of freeze-thaw splitting tensile strength, elastic modulus, and dynamic modulus.

In this paper, 3 different strengthening methods were compared to evaluate their effect on RCA. By comparing the changes in the water absorption rate and crushing value, the optimal strengthening method was selected. Then, under different cement dosages (3\%, 4\%), the mechanical properties of CSRM with different RCA contents $(0 \%, 25 \%, 50 \%, 75 \%$, and $100 \%)$ were studied. At cement dosage of $5 \%$, the $7 \mathrm{~d}$ unconfined compressive strength satisfies the requirements of the base layer of the expressway under heavy traffic load. For these RCA contents at $4 \%$ of cement dosage that does not meet the requirements of the specification, the optimal strengthening method was applied to improve the mechanical performance of CSRM. Finally, by comprehensive evaluation, the recommended RCA content was proposed corresponding to different-class highways. The outcomes of this study are expected to provide a useful reference for pavement analysis and design, thus promoting the consumption of $\mathrm{C} \& \mathrm{D}$ waste.

\section{Materials and Research Content}

2.1. Cement. The cement used in this experiment was P.C32.5. Its basic performance indicators were measured, and the results are shown in Table 1 . The standard value is obtained from China specification "General Portland $\mathrm{Ce}$ ment" [36].

2.2. Aggregate. This study mainly focused on coarse aggregates with particle size of $4.75-26.5 \mathrm{~mm}$. Due to a large number of impurities on the surface of the RCA reprocessed from $C \& D$ waste, it needs to be washed and dried before testing. RCA mainly includes recycled concrete aggregate and recycled brick. There are huge differences between them in flexural strength, permeability, and other properties [37, 38]. Therefore, the natural coarse aggregate and these two main ingredients of RCA were separated manually, as shown in Figure 1. According to the method of Chinese standard "Highway Engineering Aggregate Test Regulations" [39], the basic properties of the RCA with 3 different particle sizes were studied. And the test of water absorption rate was conducted by Volumetric flask method in this standard. The results are shown in Table 2.

According to Table 2, the water absorption rate of the recycled brick aggregate is higher than those of the natural aggregate and recycled concrete aggregate. With the increasing in brick aggregate particle size, its water absorption rate slowly decreases. The crushing values of these two main ingredients of RCA can meet the requirements of the base and subbase of China's standard "Technical Rules for Construction of Road Pavement Base Courses" [40]. But the values of the concrete aggregate and brick aggregate are $25.47 \%$ and $39.62 \%$ greater than those of natural aggregates, respectively. The difference between these two main ingredients and natural aggregates is mainly because of the differences in their surface state. There are some mortars attached on the surface of recycled concrete aggregates and recycled brick aggregates, which results in more pores on the surface of the RCA. Compared with recycled concrete aggregates, there are more mortars attached to recycled brick aggregates. Thus, the water absorption rate and crushing value of recycled brick aggregates are larger than those of recycled concrete aggregates [41, 42].

The indexes of fine aggregate are shown in Table 3.

As can be seen from Table 3, the apparent density and water absorption rate of recycled fine aggregate are, respectively, smaller and higher than those of natural fine aggregate. The water absorption rate of recycled fine aggregate is $75.65 \%$ greater than that of natural fine aggregate. This is mainly because the recycled fine aggregate is composed of some stones in the crushing process and unhydrated mortar or brick aggregate.

2.3. Grading Design. The grading of the mixture adopted the median value of the skeleton dense grading range specified in China's standard [40], as shown in Figure 2.

In order to determine the optimal moisture content (OMC) and maximum dry density (MDD) of the CSRM, the compaction test was carried out. Since the recycled brick aggregate accounted for $10 \%$ in RCA, the influence of the recycled brick aggregate on the properties of CSRM could not be ignored. The ratio between recycled concrete and recycled brick aggregate was approximately $9: 1$. Then, the natural coarse aggregate was replaced by RCA in this ratio to carry out the compaction experiment. The RCA replacement rates are $0 \%, 25 \%, 50 \%, 75 \%$, and $100 \%$. In addition, two different cement dosages (4\%, 5\%) were considered. The results are shown in Figure 3.

The following information can be obtained through Figure 3: 
TABLE 1: Cement quality index test results.

\begin{tabular}{|c|c|c|c|c|c|c|c|}
\hline \multirow[t]{2}{*}{ Detection index } & \multicolumn{2}{|c|}{ Setting time $(\min )$} & \multirow[t]{2}{*}{ Stability (mm) } & \multicolumn{2}{|c|}{$\begin{array}{c}\text { Flexural } \\
\text { strength }(\mathrm{MPa})\end{array}$} & \multicolumn{2}{|c|}{$\begin{array}{l}\text { Compressive } \\
\text { strength }(\mathrm{MPa})\end{array}$} \\
\hline & Initial setting time & Final setting time & & $3 d$ & $28 \mathrm{~d}$ & $3 \mathrm{~d}$ & $28 \mathrm{~d}$ \\
\hline Detection value & 248 & 385 & 1.0 & 3.3 & 7.1 & 18.5 & 36.2 \\
\hline Standard value & $\geq 180$ & $\geq 360$ & $\leq 5$ & $\geq 2.5$ & $\geq 5.5$ & $\geq 10.0$ & $\geq 32.5$ \\
\hline
\end{tabular}

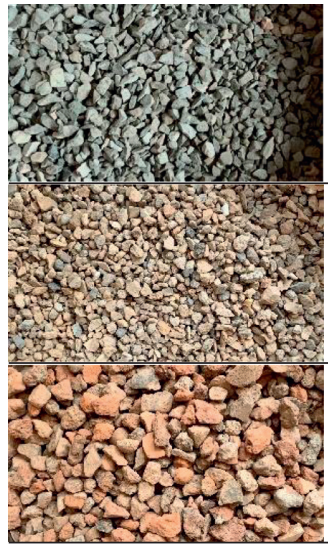

(a)

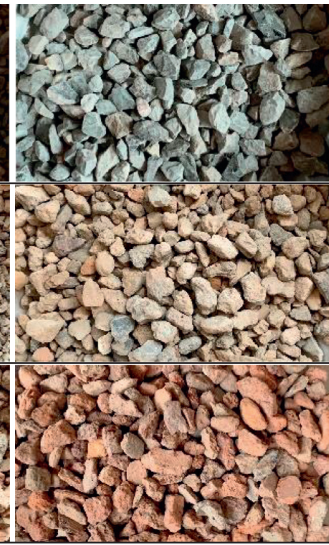

(b)

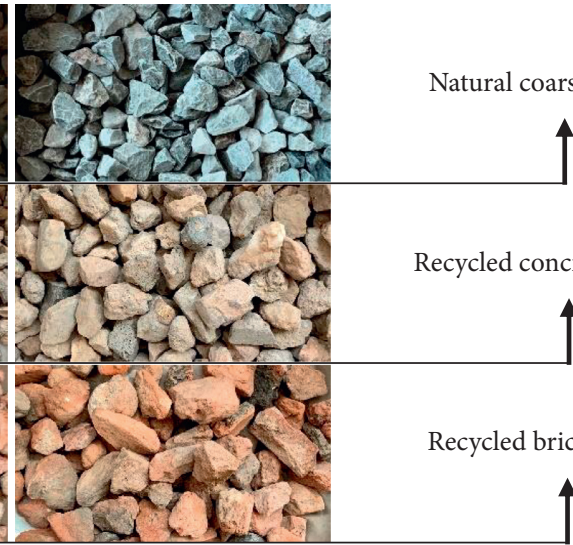

(c)

Figure 1: Natural coarse aggregate and RCA source materials. (a) 4.75-9.5 mm. (b) $9.5-19 \mathrm{~mm}$. (c) $19-26.5 \mathrm{~mm}$.

TABle 2: Prosperities of coarse aggregate.

\begin{tabular}{|c|c|c|c|c|c|c|c|c|c|}
\hline \multirow{2}{*}{ Test detection index } & \multicolumn{3}{|c|}{ Natural aggregate } & \multicolumn{3}{|c|}{ Recycled concrete aggregate } & \multicolumn{3}{|c|}{ Recycled brick aggregate } \\
\hline & $4.75-9.5$ & $9.5-19$ & $19-26.5$ & $9.5-19$ & $9.5-19$ & $19-26.5$ & $4.75-9.5$ & $9.5-19$ & $19-26.5$ \\
\hline Apparent density $\left(\mathrm{kg} / \mathrm{m}^{3}\right)$ & 2.77 & 2.76 & 2.76 & 2.50 & 2.54 & 2.56 & 2.31 & 2.27 & 2.29 \\
\hline Water absorption rate $(\%)$ & 0.67 & 0.53 & 0.41 & 5.71 & 5.44 & 5.23 & 17.08 & 16.55 & 14.61 \\
\hline Needle particles (\%) & 8.3 & 7.8 & 4.5 & 7.6 & 6.9 & 5.7 & 8.9 & 7.3 & 5.2 \\
\hline Crushing value (\%) & & 21.2 & & & 26.6 & & & 29.3 & \\
\hline
\end{tabular}

TABle 3: Prosperities of fine aggregate.

\begin{tabular}{lcc}
\hline Detection index & Natural fine aggregate & Recycled fine aggregate \\
\hline Apparent density $\left(\mathrm{kg} / \mathrm{m}^{3}\right)$ & 2.68 & 2.35 \\
Water absorption rate $(\%)$ & 4.23 & 7.43 \\
Liquid limit $(\%)$ & 22.6 & 28.2 \\
Plastic limit $(\%)$ & 14.9 & 22.3 \\
\hline
\end{tabular}

(1) As the content of RCA increases, the MDD of the CSRM decreases and its OMC increases, regardless of the cement dosage. Taking the cement dosage of $4 \%$ as an example, when the content of RCA increases from $0 \%$ to $100 \%$, the MDD decreases from $2.32 \mathrm{~g} / \mathrm{cm}^{3}$ to $1.90 \mathrm{~g} / \mathrm{cm}^{3}$. The OMC increases from $4.11 \%$ to $10.52 \%$.

(2) The MDD and the OMC of the CSRM, respectively, increase and decrease with the increase of cement dosage regardless of the RCA contents. This is mainly because more water is needed to hydrate the CSRM with the increase of cement dosage. During the compaction, hydrated products will gradually fill the voids of the CSRM, which contributes to the increase of the MDD.
2.4. Research Content. This article mainly studies different strengthening methods for strengthening the RCA and mechanical properties of CSRM with different cement dosages. In each cement dosage (4\%, $5 \%$ ), five different RCA contents $(0 \%, 25 \%, 50 \%, 75 \%$, and $100 \%)$ were considered. The research contents are as follows:

(1) Basic material performance tests were conducted to compare the performance of RCA and natural aggregates. The main performance indicators were apparent density, water absorption, crushing value, etc.

(2) Three different strengthening methods were adopted to strengthen the RCA. Different working conditions were set in each method. For the Los Angeles (LA) 


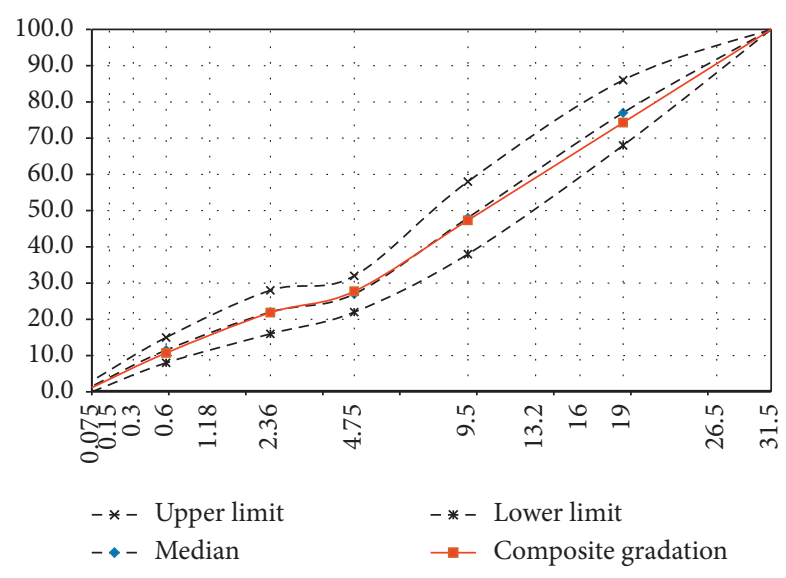

Figure 2: Design diagram of the gradation curve of framework dense structure.

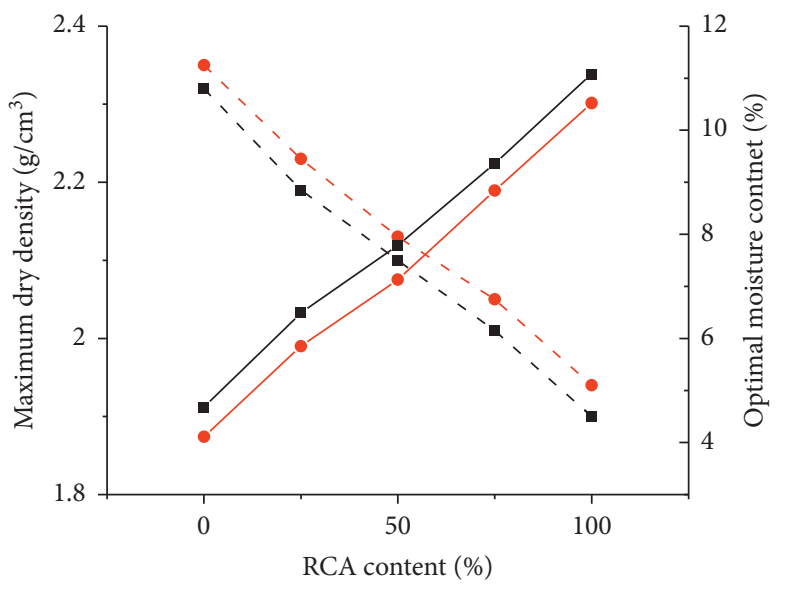

- - MDD at $4 \%$ of cement dosage

- - MDD at $5 \%$ of cement dosage

$\rightarrow$ OMC at $4 \%$ of cement dosage

$\rightarrow$ OMC at $5 \%$ of cement dosage

FIgURE 3: Results of the compaction test under different RCA content and cement dosages.

abrasion test, three different revolutions and steel balls were considered. For chemical strengthening tests, solution concentration and soaking time were two variables considered for experiments. Water absorption rate and crushing value were used as evaluation indexes to get the best strengthening method.

(3) The diagram of the gradation curve was made to meet the grading range given by the specification. Then, the compaction experiments were conducted to research the OMC and the MDD under different contents of RCA and cement dosage.

(4) According to the results in compaction tests, the mechanical properties experiments were conducted. These experiments included unconfined compressive strength, splitting strength, and compressive rebound modulus tests. By analyzing the influence of cement dosage and the RCA content on the performance of CSRM, a recommended range of RCA was obtained in road engineering.

(5) For the content of RCA that does not meet the requirements of the specification, the best strengthening method obtained in the previous tests was utilized to strengthen the RCA. By comparing three mechanical properties before and after strengthening, the recommended content of RCA after strengthening was obtained.

\section{Aggregates Treatment}

3.1. LA Abrasion Test. LA abrasion test is a physical strengthening method, designed to make RCA collide with steel balls. After friction, the surface of the mortar was shedding, thus obtaining reinforced aggregates. Turns of the LA abrasion test (200, 400, and 800) and steel balls (4, 8, and 12) were used as two variables in this experiment. To carry out this experiment, $5 \mathrm{~kg}$ each of recycled concrete aggregate and recycled brick aggregate was utilized. The water absorption rate and crushing value of the RCA after strengthening are shown in Figure 4.

It can be seen from Figure 4 that the water absorption rate and crushing value take the minimum value at $400 \mathrm{r}$. From 0 to 400r, the water absorption rate and crushing value of the RCA decrease. The water absorption rates of recycled concrete aggregate and recycled brick aggregate decrease by $1.21 \%$, and $0.72 \%$, respectively. The crushing values related to these materials decrease by $3.7 \%$ and $4.36 \%$, respectively. When the cycles increase from 400 to 600 r, they show an upward trend. For recycled concrete aggregate, the water absorption rate and crushing value averagely increase by $0.07 \%$ and $0.4 \%$, respectively. For recycled brick aggregate, they sharply increase by $0.31 \%$ and $0.86 \%$, respectively. This fact is because microcracks on the surface of RCA arise as the number of turns increases, and this phenomenon increases its water absorption and crushing values. But for recycled brick aggregate, it causes cracks and even damage. As shown in Figure 4(b), by colliding with 12 steel balls, the water absorption rate and crushing value increase from 400 to $600 \mathrm{r}$. The greater the number of steel balls, the greater the damage to the recycled brick aggregate. That is the reason why the greater the number of steel balls for recycled brick aggregate, the greater the increase in water absorption rate. It can be easily concluded that the 12 steel balls and $800 \mathrm{r}$ are the most proper condition.

3.2. Sodium Silicate Solution. The colloidal particle structure in the sodium silicate solution can be expressed by Figure 5, and the hydrolysis reaction can be briefly summarized as (1). Sodium silicate solution can react with calcium hydroxide to form C-S-H gel as shown in (2):

After mixing the sodium silicate solution and RCA, the surface of aggregate is coated with a thin layer of sodium silicate film, that is, the adhesive film [43]. Adjacent aggregates are connected by an adhesive film to 

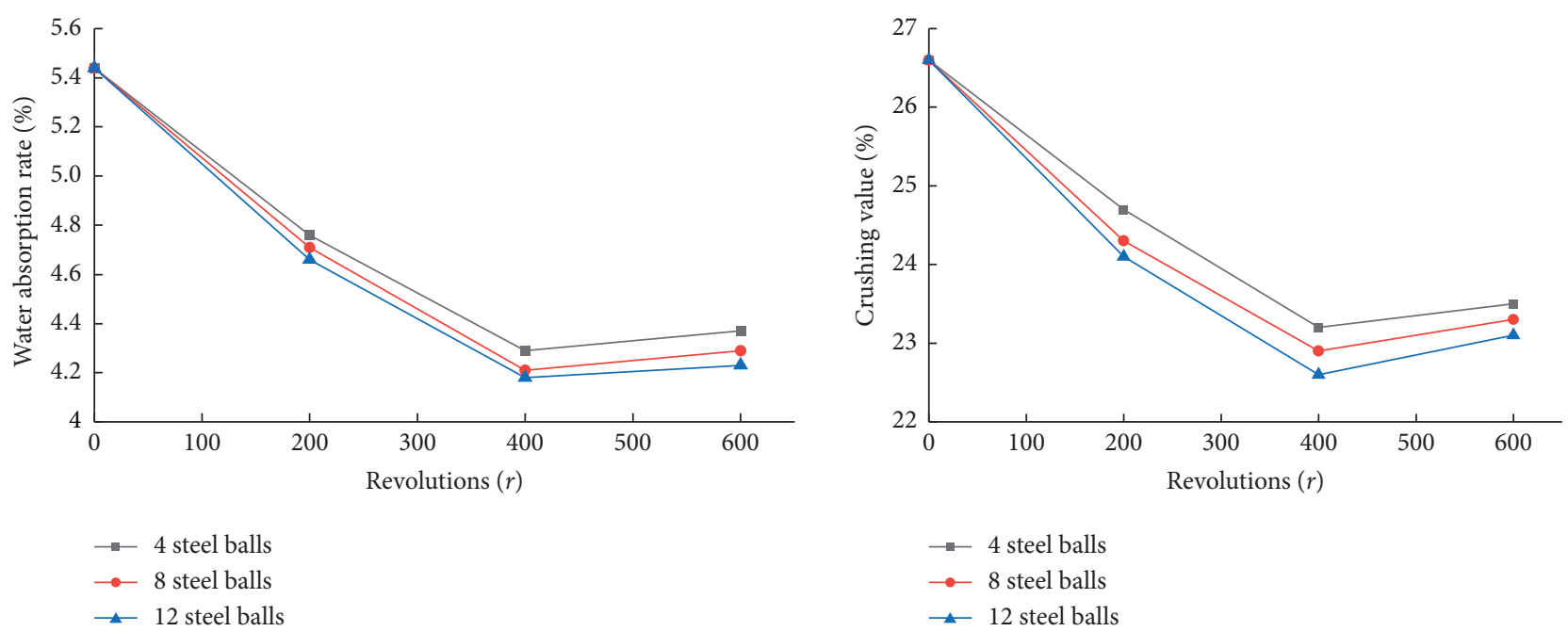

(a)
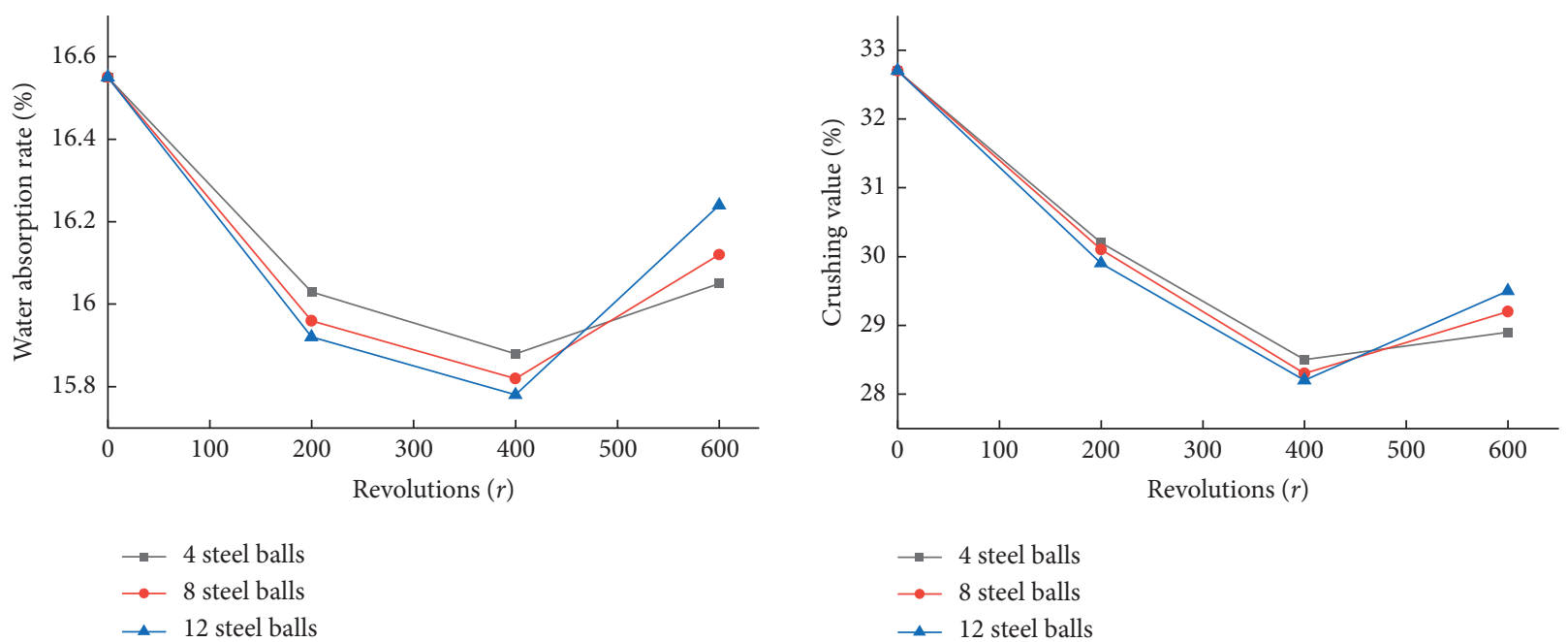

(b)

FIgURE 4: Results of the LA abrasion test. (a) Recycled concrete aggregate. (b) Recycled brick aggregate.

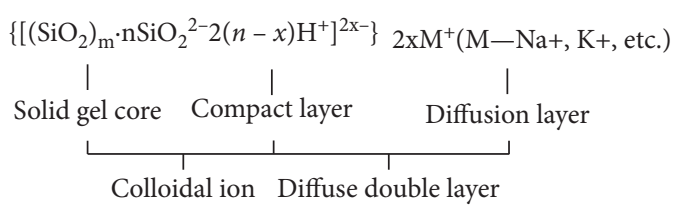

FIGURE 5: Colloidal particle structure in sodium silicate solution.

form an adhesive bridge (Figure 6). Then, the adhesive strength is established through the gelation process of sodium silicate.

$$
\mathrm{NaO}+n \mathrm{SiO}_{2}+2 n \mathrm{H}_{2} \mathrm{O}+\mathrm{CO}_{2}=2 \mathrm{Na}_{2} \mathrm{CO}_{3}+n \mathrm{Si}(\mathrm{OH})_{4},
$$

$$
\mathrm{Na}_{2} \mathrm{SiO}_{3}+\mathrm{Ca}(\mathrm{OH})_{2}+\mathrm{H}_{2} \mathrm{O} \longrightarrow \mathrm{C}-\mathrm{S}-\mathrm{H}+\mathrm{NaOH}
$$

The basic indicators of sodium silicate solution are shown in Table 4.
The mass percentage of the sodium silicate solution was $41.64 \%$. By adding water, it was prepared at $5 \%$. To ensure that the solution can fully submerge the aggregate, the sorted recycled concrete aggregate and recycled brick aggregate were poured into the sodium silicate solution and stirred evenly. At the soaking time of $2 \mathrm{~h}, 5 \mathrm{~h}$, and $10 \mathrm{~h}$, the recycled concrete aggregate and the brick aggregate were taken out and filtered out. Then, they were spread on the enamel tray to naturally dry in the room. The water absorption rate and crushing value of the dried aggregates are measured. The above operation was repeated with $8 \%$ and $12 \%$ sodium silicate solution. The results are shown in Figure 7.

It can be seen from Figure 7 that as the strengthening time increases, the water absorption rate of two main compositions of RCA decreases at a concentration of 5\%. As the substances in the sodium silicate solution react with the old mortar on the surface of the RCA, the hydrated silica colloid fills the pores and cracks on the surface of the aggregate. The change in crushing value also meets this law. 


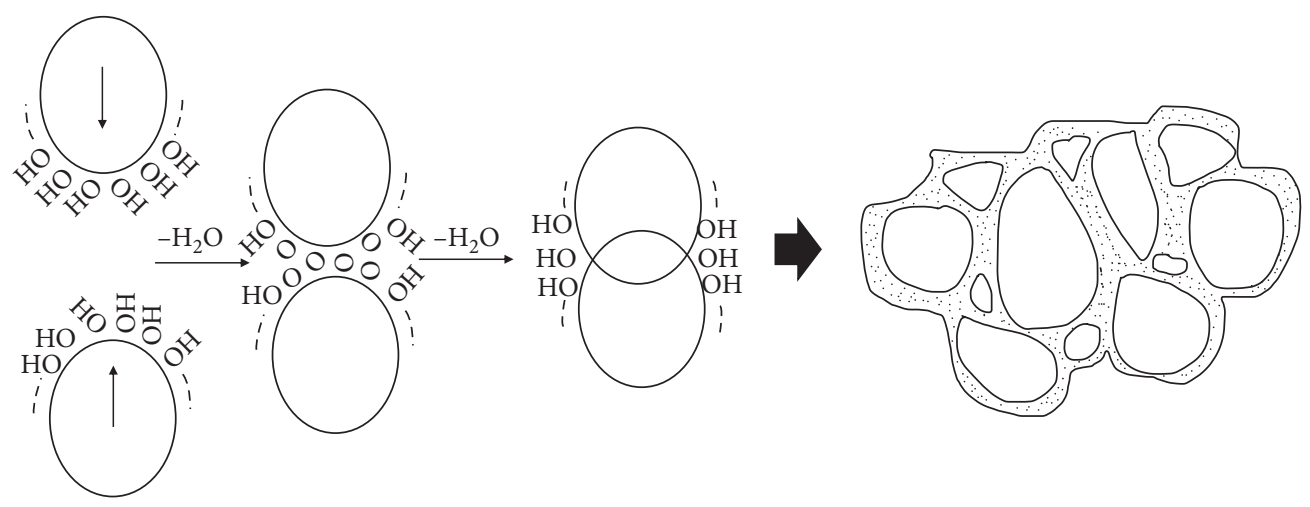

FIGURE 6: Adhesive strength forming process.

TABLE 4: The basic indicators of sodium silicate solution.

\begin{tabular}{lccc}
\hline Baume degree $\left({ }^{\circ} \mathrm{Bé}\right)$ & $\mathrm{Na}_{2} \mathrm{O}(\%)$ & $\mathrm{SiO}_{2}(\%)$ & Modulus $(M)$ \\
\hline 39 & 8.2 & 26 & 3.1 \\
\hline
\end{tabular}

For recycled concrete aggregate, its water absorption rate and crushing value, respectively, decrease $1.21 \%$ and $1.5 \%$ when soaking from 0 to $10 \mathrm{~h}$; for recycled brick aggregate, these two indexes decrease $3.99 \%$ and $4.6 \%$. When the concentration is $8 \%$ and $12 \%$, the higher the concentration of the sodium silicate solution, the more intense the reaction with the mortar on the surface of the RA, and more C-S-H gel will also be produced. Therefore, the water absorption rate and crushing value reach the maximum in the $5 \mathrm{~h}$ of strengthening time. As strengthening time increases, the sodium silicate solution will form a coating on the surface of the RCA and the layer thickness gradually increases, which in turn causes the decrease of its strength [44]. In terms of water absorption rate, it is when the concentration is $8 \%$ and strengthening is five hours that the value reaches the minimum. The crushing value associated with $12 \%$ sodium silicate solution is slightly lower than that of $8 \%$. But at $12 \%$, the crushing value is more sensitive. With the increase of strengthening time, its value decreases.

3.3. Titanate Coupling Agent. The titanate coupling agent used in this experiment was TM-200S. The mechanism of titanate coupling agent has always been an issue to research. There are many coupling theories about the coupling agent [45-47]. The principle of chemical bond is the most traditional and classical theory in the theory of coupling between the titanate coupling agent and inorganic filler [48]. It was proposed that titanium-derived coupling agents react with free protons at the inorganic interface to form organic monomolecular layers on the inorganic surface. The compatibilization of the inorganic/organic phase resulted in new composite property, catalysis, adhesion, and rheology performance. Its structural composition and action mechanism are shown in Figures 8 and 9.

In this figure, $1 \leq \mathrm{M} \leq 4, \mathrm{M}+\mathrm{N} \leq 6$; $\mathrm{R}$ is short chain alkane group; $\mathrm{R}^{\prime}$ is long chain alkane group; $\mathrm{X}$ is $\mathrm{C}, \mathrm{N}, \mathrm{P}, \mathrm{S}$, etc.; $\mathrm{Y}$ is group of hydroxy, amino, epoxy, double bond, etc.
To carry out the experiments, $2 \mathrm{~kg}$ of $10 \mathrm{~mm}$ and $20 \mathrm{~mm}$ recycled brick aggregate and recycled concrete aggregate was poured into titanate coupling agent solution $(1 \%, 2 \%$, and $3 \%)$. The soaking time was $1 \mathrm{~h}, 2 \mathrm{~h}, 3 \mathrm{~h}$, $4 \mathrm{~h}$, and $5 \mathrm{~h}$. After reaching the specific strengthening time, they were taken out and dried indoors. Finally, the water absorption rate and crushing value were measured according to the method in the specification. The results are shown in Figure 10.

It can be seen from Figure 10 that as the strengthening time increases, the water absorption rate and crushing value of the RCA also gradually decrease. The water absorption rate and crushing value rapidly decrease within $1-3 \mathrm{~h}$ of strengthening time. After $3 \mathrm{~h}$, the water content and crush value tend to be stable. As the concentration of the titanate coupling agent increases from $1 \%$ to $2 \%$, a hydrophobic layer can be formed on the surface of the RCA after the hydrolysis of the coupling agent. The number of pores on the surface of the aggregate decreases, thus strengthening RCA. By chemical reaction with the inorganic filler, the surface of the filler is coupled and cross-linked with the polymer matrix to combine two substances with different properties. It can form a monomolecular covering film on the surface of the filler, which contributes to improving its inherent hydrophilic properties and preventing moisture from entering into the aggregate. Lu et al. [49] also applied this principle to the surface modification of microfibrillated cellulose. The optimal concentration of the titanate coupling agent is determined by the RCA particle size and conditions of the surface functional group. The finer the filler particle size and the larger the surface area, the greater the amount of coupling agent used. When the strengthening time is $4 \mathrm{~h}$ and the concentration of titanate coupling agent is $2 \%$, the effect of enhancement is the best.

By comprehensive comparison, the best working conditions of each strengthening methods are listed as follows:

(1) Method 1: colliding with 12 steel balls and spinning $100 \mathrm{r}$ in the LA abrasion tester

(2) Method 2: strengthening by $8 \%$ sodium silicate solution for $5 \mathrm{~h}$

(3) Method 3: strengthening with a 2\% titanate coupling agent solution for $4 \mathrm{~h}$ 

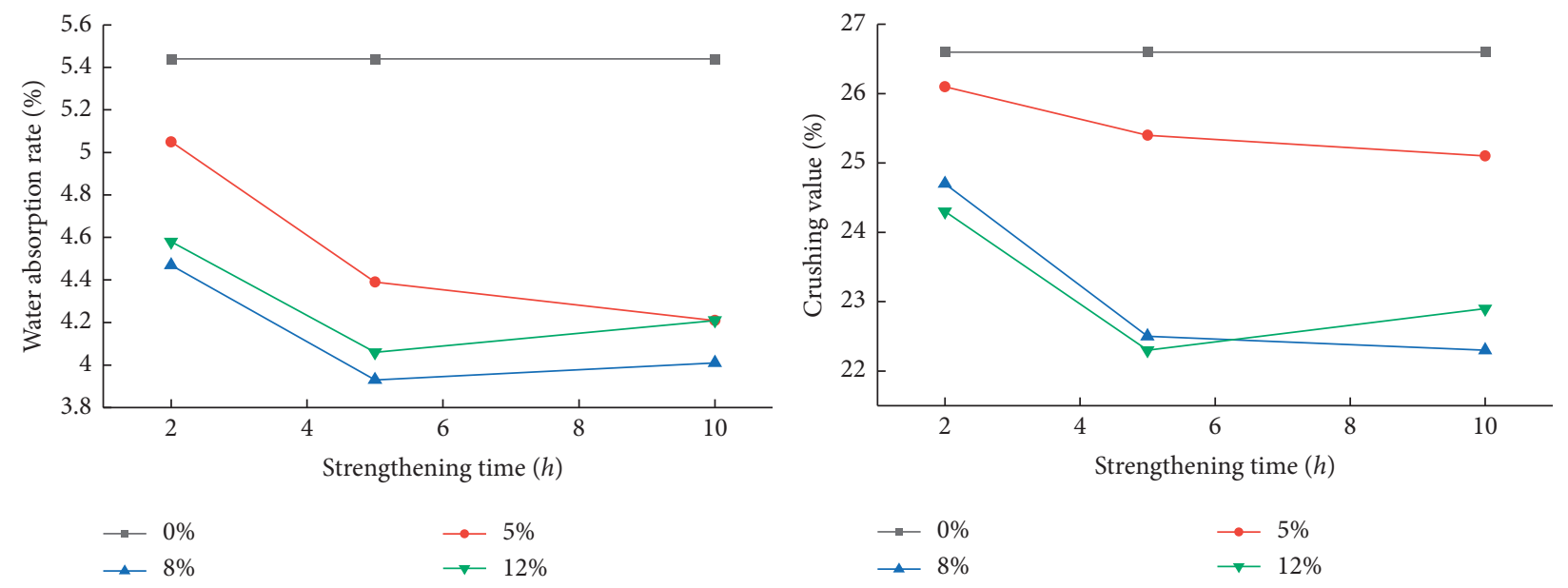

(a)
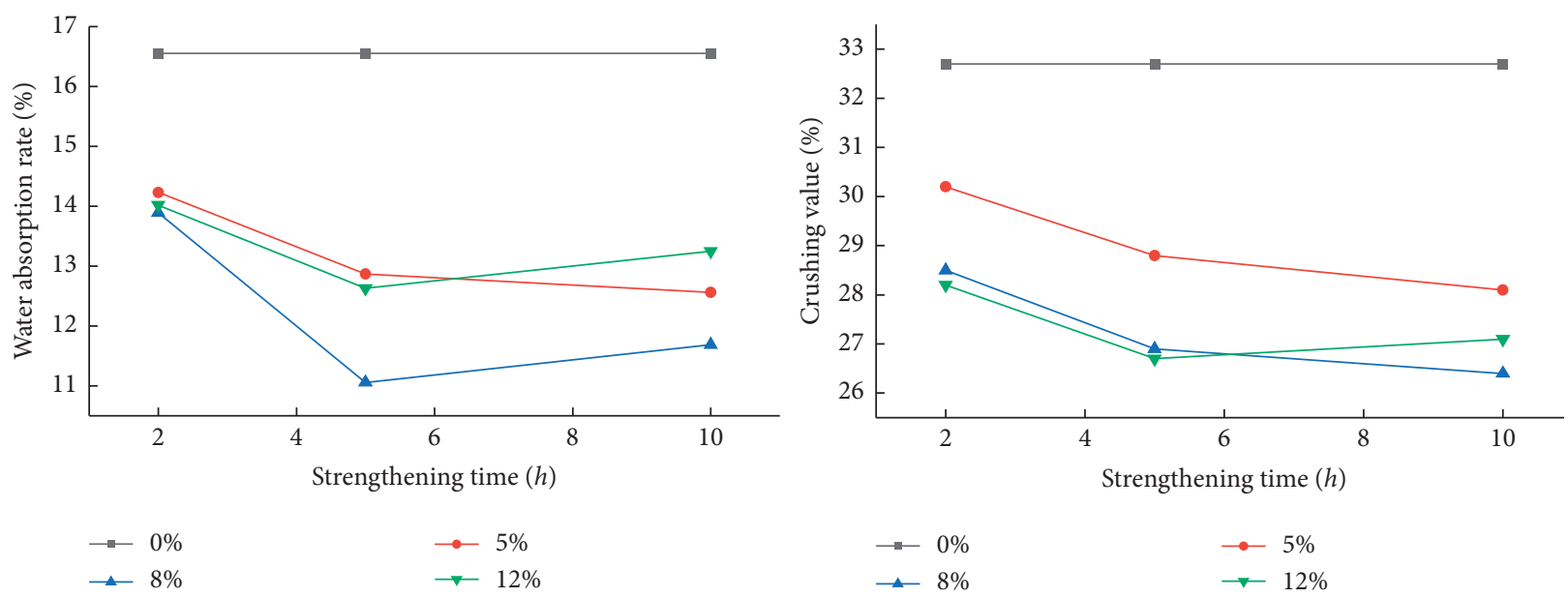

(b)

FIGURE 7: Results of sodium silicate solution. (a) Recycled concrete aggregate. (b) Recycled brick aggregate.

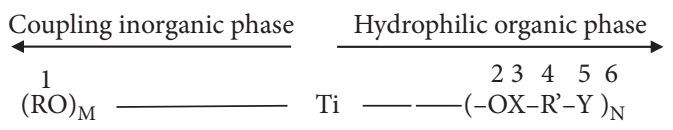

FIgURE 8: The formula of titanate coupling agent.

The results of the above three strengthening methods are shown in Figure 11.

Through Figure 11, it can be clearly seen that the sodium silicate solution is the most ideal strengthening method. In this way, the water absorption rate and crushing value of the RCA are less than those of the other two strengthening methods. Specifically, the crushing value of RCA is close to that of natural aggregate, and the water absorption rate has also been greatly improved. Regarding the crushing value, the standard requires that the subbase layer of the first-class highways and expressway should not be higher than $26 \%$. By strengthening with a $26 \%$ titanate coupling agent solution for $4 \mathrm{~h}$, the crushing value of the recycled asphalt mixture can reach $24.6 \%$, which meets the standard requirements [40]. For recycled concrete aggregate, the strengthening effect of the LA abrasion tester is better than the titanate coupling agent. For recycled brick aggregate, the effect of the titanate coupling agent is better than the LA abrasion tester. Based on the above analysis, the best strengthening method is strengthening with a concentration of $8 \%$ and strengthening for $5 \mathrm{~h}$.

\section{Results and Discussion}

4.1. Unconfined Compressive Strength. The unconfined compressive strength tests were carried out according to T0805-2009 test method in the standard [50]. The results are shown in Figure 12.

In this figure, $K$ indicates the RCA content.

By analyzing Figure 12, it is possible to conclude that, during the curing period of the CSRM from $7 \mathrm{~d}$ to $90 \mathrm{~d}$, the strength growth rate from $7 \mathrm{~d}$ to $28 \mathrm{~d}$ is faster than that from $28 \mathrm{~d}$ to $90 \mathrm{~d}$. Taking the dosage of $4 \%$ cement as an example, when the content of RCA increased from $0 \%$ to $100 \%$, the unconfined compressive strength from $7 \mathrm{~d}$ to $28 \mathrm{~d}$ increases by an average of $35.02 \%$ compared to the stage from $28 \mathrm{~d}$ to $90 \mathrm{~d}$. It is confirmed that the hydration reaction of cement mainly occurs in the early stage. 


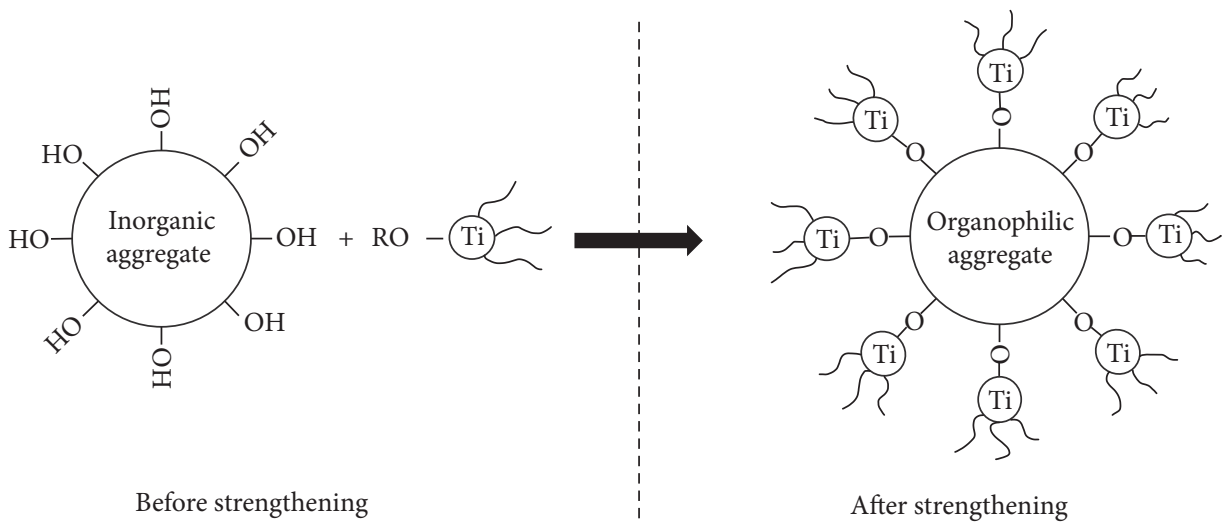

FIgURE 9: Mechanism of titanate coupling agent.
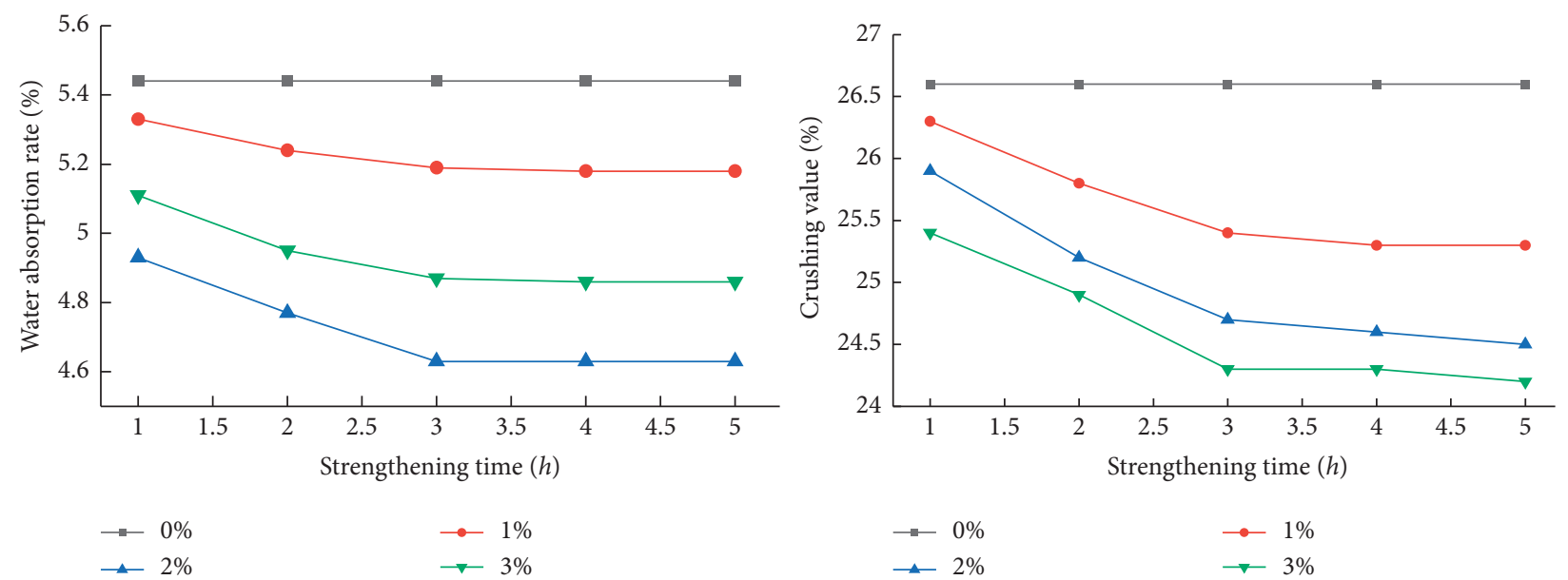

(a)
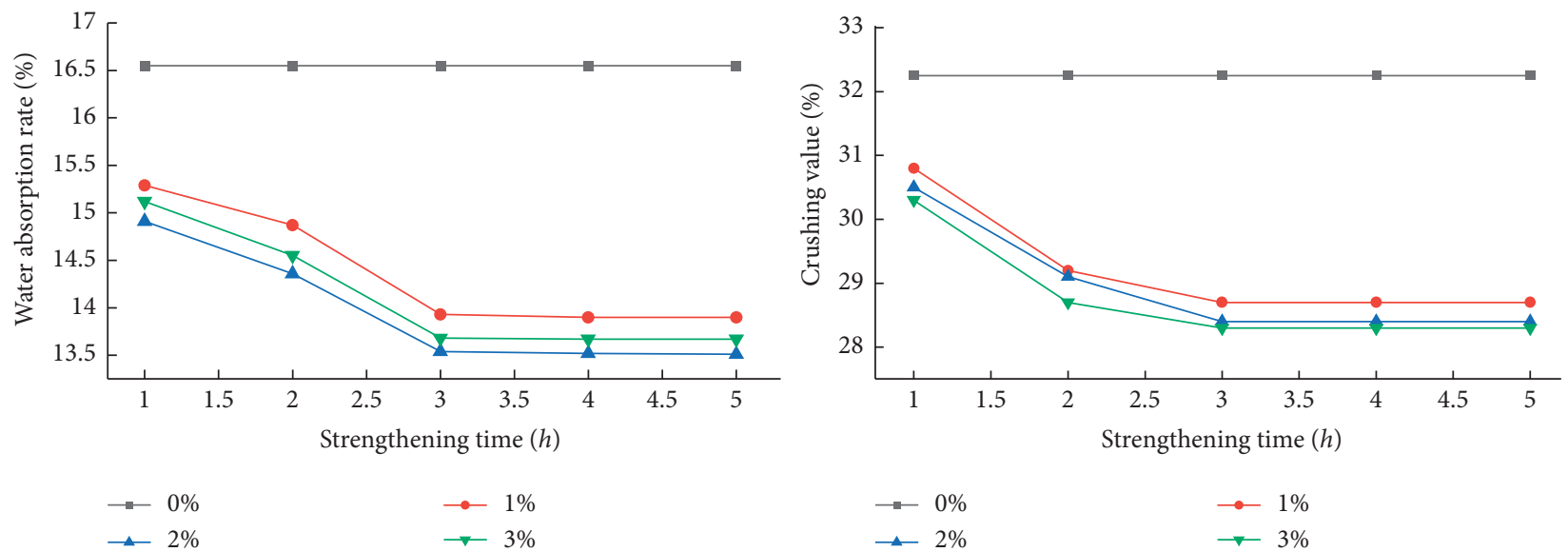

(b)

FIgURE 10: Results of titanate coupling agent. (a) Recycled concrete aggregate. (b) Recycled brick aggregate.

Moreover, when the cement dosage is $4 \%$ and the age is $7 \mathrm{~d}$, the unconfined compressive strength corresponding to the $25 \%$ RCA content is the maximum, 4.16 MPa. Compared with the $90 \mathrm{~d}$ unconfined compressive strength of cement stabilized natural mixture, that parameter related to CSRM increases by $5.33 \%$ in the
$25 \%$ of RCA content, while it decreases by $10.22 \%$, $14.89 \%$, and $19.33 \%$ under the condition of $50 \%, 75 \%$, and $100 \%$ RCA content, respectively. Studies have shown that old mortar is contained in a suitable content of RCA. And its rough surface makes benefits to the binding of aggregates and cement. For the cement dosage of $4 \%$, 


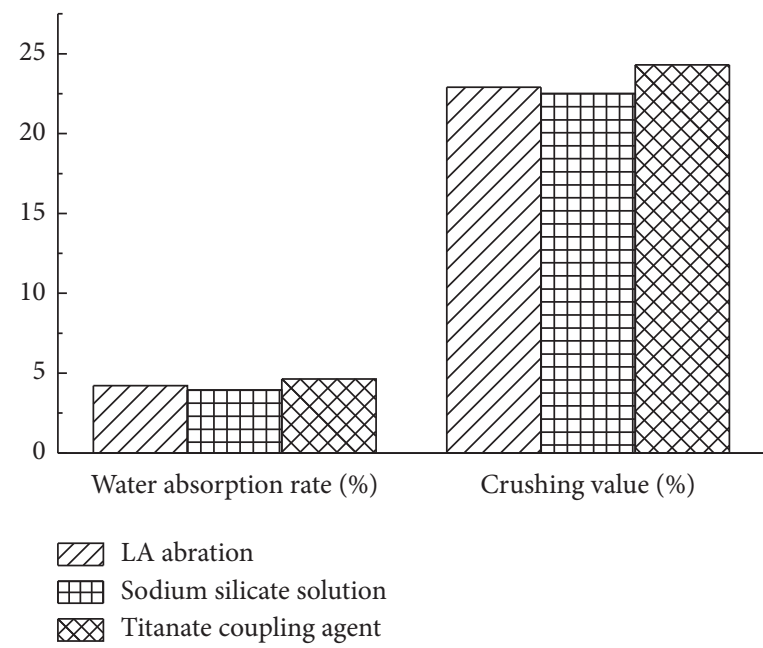

(a)

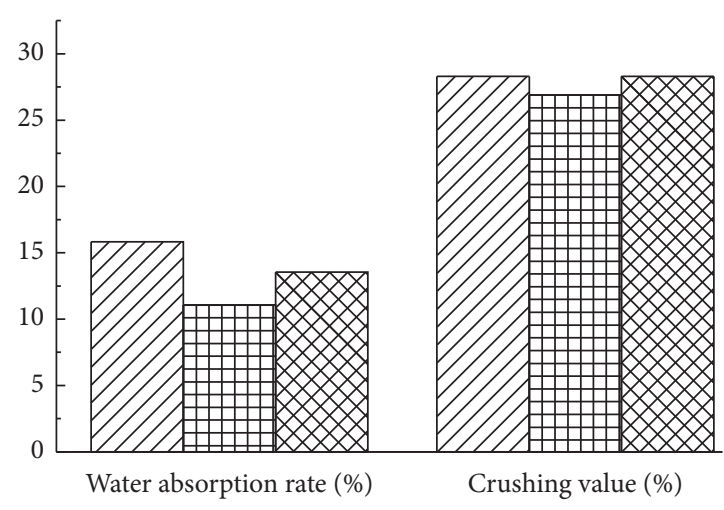

ZZZ LA abrasion

$\boxplus$ Sodium silicate solution

XX Titanate coupling agent

(b)

FIGURE 11: Comparison of three strengthening methods. (a) Recycled concrete aggregate. (b) Recycled brick aggregate.

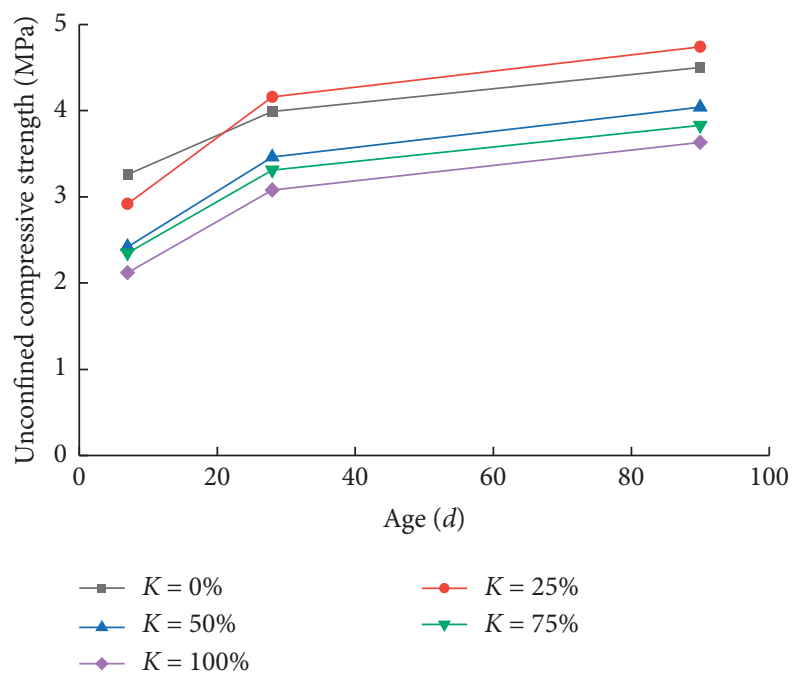

(a)

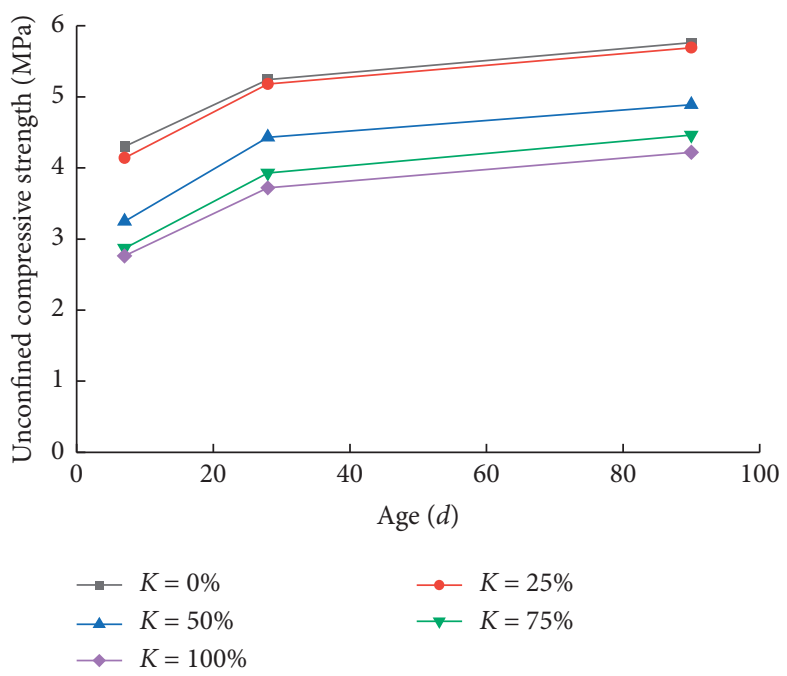

(b)

FIGURE 12: Unconfined compressive strength of CSRM at different cement dosages. (a) $4 \%$ and (b) $5 \%$.

when the curing age is $28 \mathrm{~d}$ and $90 \mathrm{~d}$, the unconfined compressive strength of the CSRM firstly increases and then decreases with the increase of the RCA content. As the curing age grows, there is some unreleased bound water in the RCA. The water is released to promote the progress of hydration. When the content of RCA exceeds a certain limit, the mechanical properties of CSRM deteriorate. Some studies also obtained the same conclusion from the perspective of microanalysis and macroperformance $[42,51]$. Unlike the trend of unconfined compressive strength in cement dosage of $4 \%$, the strength of the mixture decreases with the cement dosage of $5 \%$ when the RCA content increases. As the cement dosage increases, the disadvantage of low strength with RCA becomes more and more obvious, which makes the overall strength of the CSRM decrease.
4.2. Splitting Strength. The results of the splitting tests are shown in Figure 13.

It can be seen from Figure 13 that the changing trend of the splitting strength of CSRM is roughly the same as that of unconfined compressive strength. This fact is because the splitting strength under the same material has a certain correlation with the unconfined compressive strength. At a cement dosage of 4\%, the splitting strength increases firstly and then decreases with the increase of RCA content. The maximum splitting strength appears at $25 \%$ of the RCA content in all ages. At a certain content of RCA, the characteristics of the old mortar attached to the RCA and its rough surface play a greater advantage than the shortcomings of its strength. When exceeding this ratio, as the RCA content increases, the splitting strength decreases. Compared with the $90 \mathrm{~d}$ splitting strength of cement stabilized natural mixture, its value decreases by $5.36 \%, 16.07 \%$, and $26.79 \%$ under 


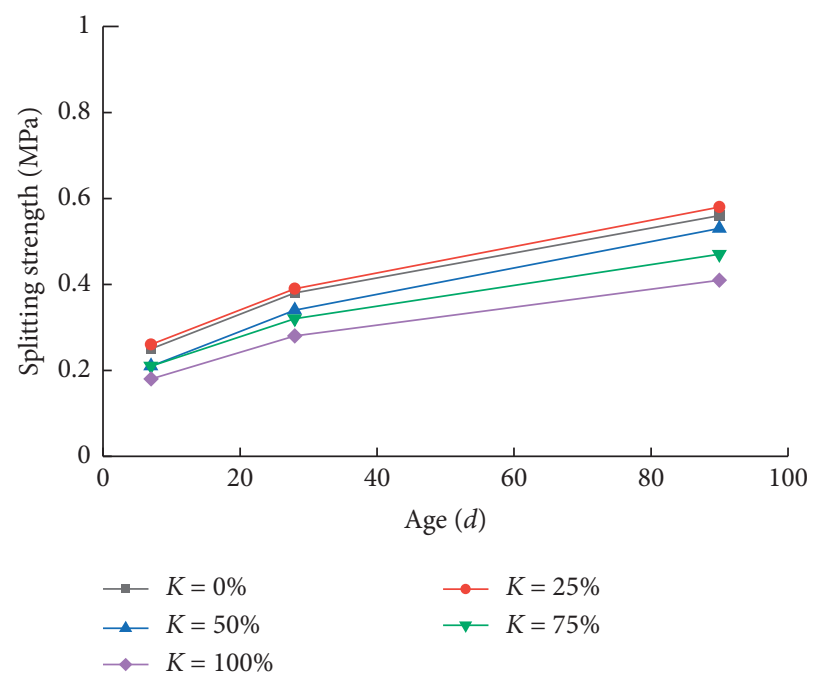

(a)

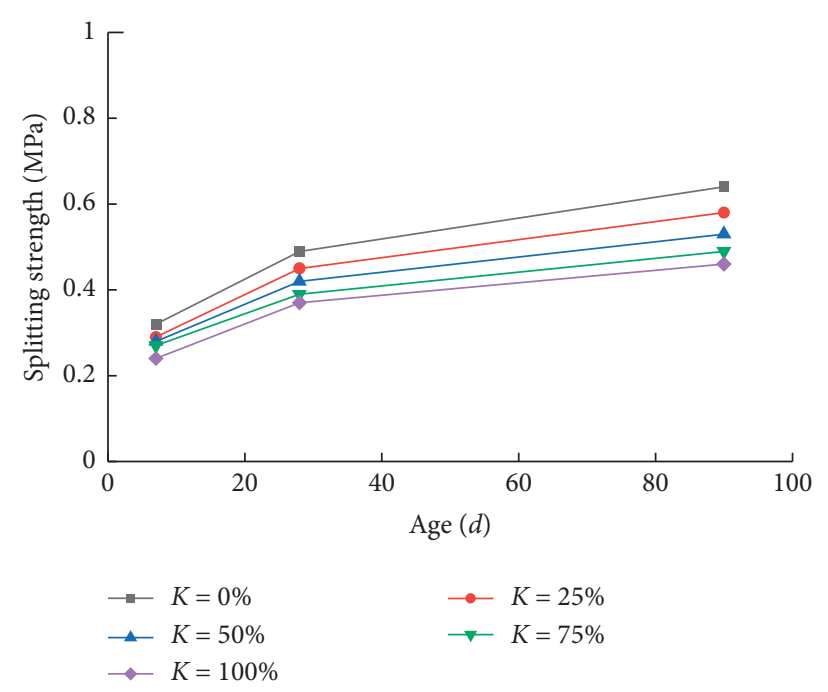

(b)

FIGURE 13: Splitting strength of CSRM at different cement dosage. (a) $4 \%$ and (b) $5 \%$.

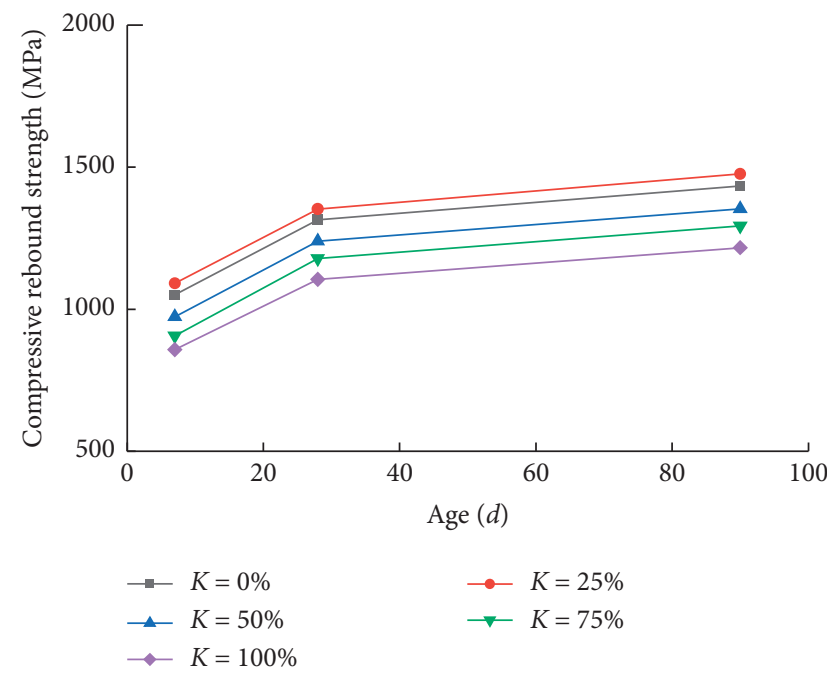

(a)

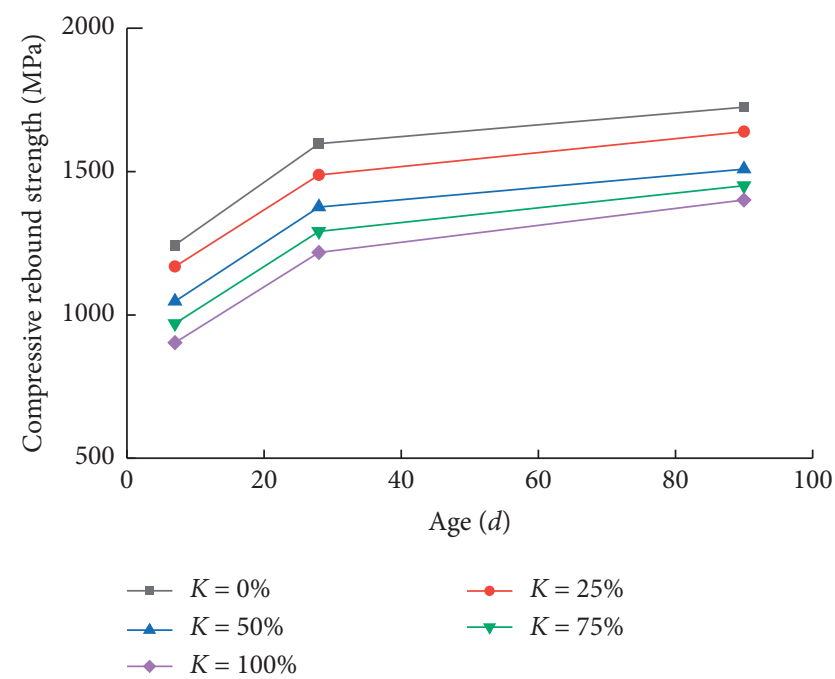

(b)

FIGURE 14: Compressive rebound strength of CSRM at different cement dosage. (a) 4\% and (b) 5\%.

the condition of $50 \%, 75 \%$, and $100 \%$ of RCA content. When the cement dosage is $5 \%$, as the RCA content increases, the strength of the mixture gradually decreases, which is caused by the defects of its strength. The $90 \mathrm{~d}$ average strength of CSRM with a 5\% cement dosage is $0.622 \mathrm{MPa}$, which is $0.112 \mathrm{MPa}$ higher than that of $4 \%$ cement dosage, while the $7 \mathrm{~d}$ average strength with $5 \%$ cement dosage is only $0.06 \mathrm{MPa}$ larger than that of $4 \%$. As the curing age increases, the advantage in the strength of the high cement dosage is gradually revealed.

4.3. Compressive Rebound Modulus. The results of the compressive rebound modulus tests are shown in Figure 14.

It can be noticed from Figure 14 that the change law of the compressive rebound modulus is the same as the two mechanical properties measured before. Compared with the $5 \%$ cement dosage, the strength is lower at the $4 \%$ cement dosage. Taking the cement stabilized natural mixture as an example, the $90 \mathrm{~d}$ compressive rebound strength of $5 \%$ cement dosage is $291.67 \mathrm{MPa}$ greater than that of $4 \%$. At $5 \%$ cement dosage, the $7 \mathrm{~d}$ unconfined compressive strength satisfies the requirements of the expressway base layer under heavy traffic load. Except for the $0 \%$ and $25 \%$ of RCA content, the value of splitting strength and compressive rebound modulus of $4 \%$ of cement dosage fail to meet the requirements of China standard "Highway Asphalt Pavement Design Criterion" [52] in the other content. In the existing research, there is no scientific basis to support the use of RCA to replace $100 \%$ of natural aggregates in the pavement base layer. 

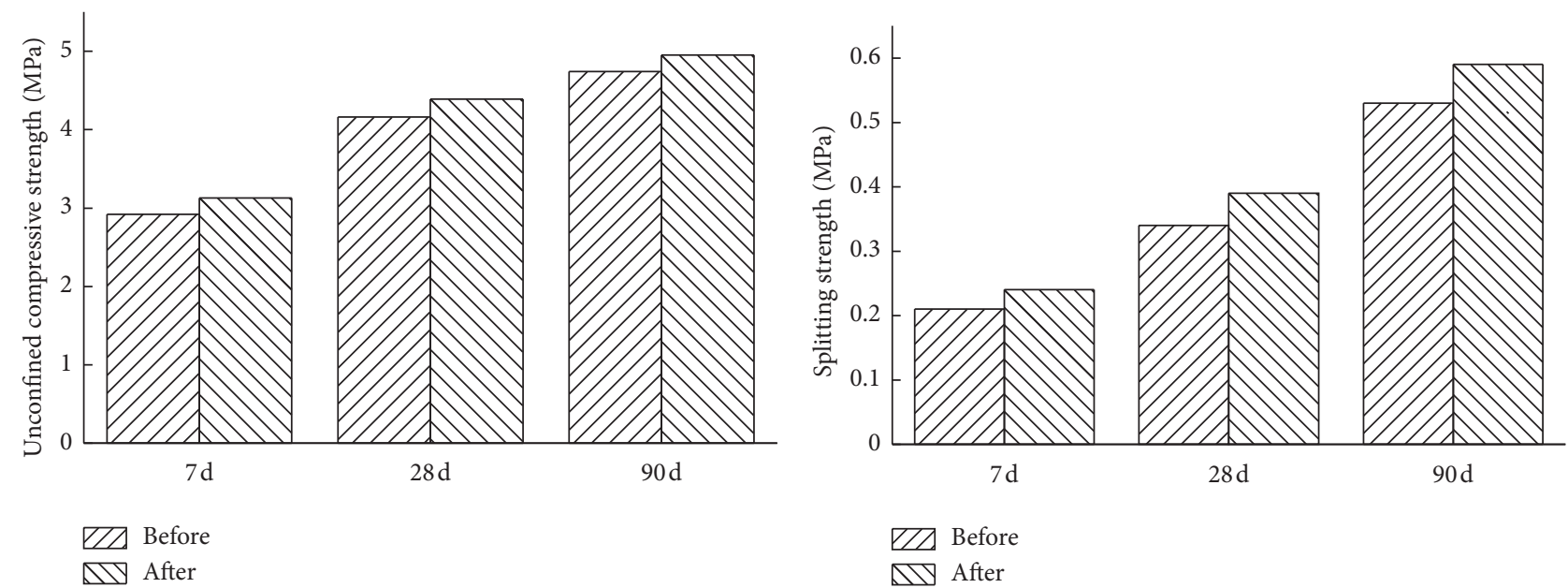

(a)

\begin{abstract}
ZZZ Before
\end{abstract}
MI After

(b)

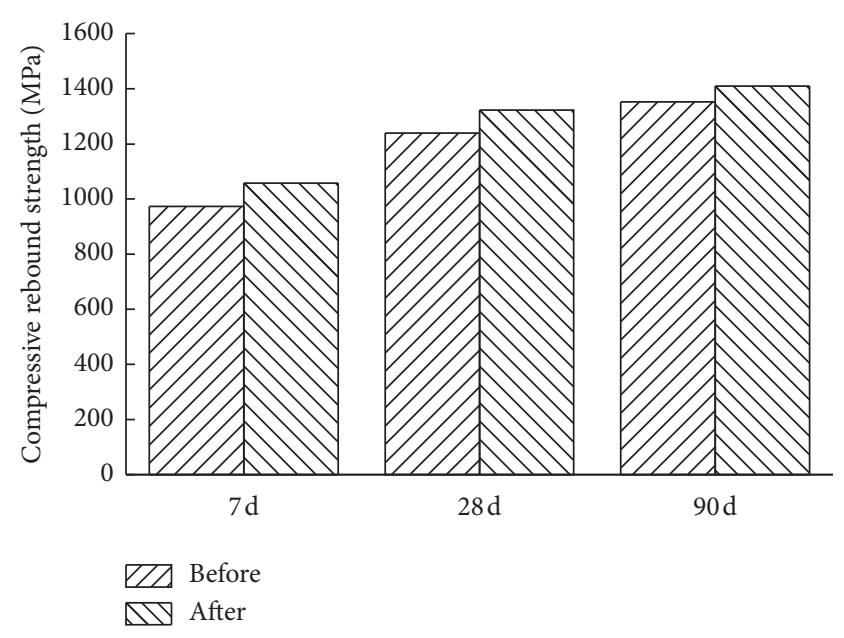

(c)

Figure 15: Mechanical performance results under 50\% of RCA content. (a) Unconfined compressive strength. (b) Splitting strength. (c) Compressive rebound modulus.

Therefore, in this paper, the CSRM with two different RCA contents $(50 \%, 75 \%)$ at $4 \%$ cement dosage were strengthened.

4.4. Comprehensive Evaluation. As can be seen from the strengthening method section in this study, $8 \%$ sodium silicate solution and strengthening for $5 \mathrm{~h}$ are the best strengthening method. Firstly, by strengthening the RCA and then comparing the mechanical properties of CSRM with $50 \%$ and $75 \%$ RCA contents, the range of the RCA content strengthening with sodium silicate solution was recommended. The unconfined compressive strength, splitting strength, and compressive rebound modulus were measured at 50\% RCA content before and after strengthening. The results are shown in Figure 15.

It can be seen from Figure 15 that the unconfined compressive strength of $7 \mathrm{~d}$ after strengthening increases from $2.92 \mathrm{MPa}$ to $3.13 \mathrm{MPa}$, which represents an increase of $7.19 \%$. The splitting strength of $7 \mathrm{~d}$ increases from $0.21 \mathrm{MPa}$ to $0.24 \mathrm{MPa}$. It means an increase of $14.29 \%$. The compressive rebound modulus of $7 \mathrm{~d}$ increases from $973.06 \mathrm{MPa}$ to $1058.39 \mathrm{MPa}$. In this case, the parameter increases by $8.77 \%$. According to the standard [52], the strength of CSRM with 50\% RCA content after strengthening can meet the requirements of the subbase for expressways and first-class highways.

The results of the mechanical performance of CSRM at $75 \%$ content of RA are shown in Figure 16.

It can be seen from Figure 16 that the $7 \mathrm{~d}$ unconfined compressive strength after strengthening increases from 2.12 MPa to $2.69 \mathrm{MPa}$, which represents an increase of $26.89 \%$. The splitting strength of $7 \mathrm{~d}$ increases from $0.18 \mathrm{MPa}$ to $0.22 \mathrm{MPa}$. It means an increase of $22.22 \%$. The compressive rebound modulus of $7 \mathrm{~d}$ increases from $857.31 \mathrm{MPa}$ to 947.32 MPa. In this case, it increased by $10.5 \%$. The reason for its strength improvement is that the sodium silicate solution fills some pores on the surface of the RCA. It can be clearly seen that the mechanical properties of the CSRM in 100\% RCA content have been greatly improved, especially reflected in the 


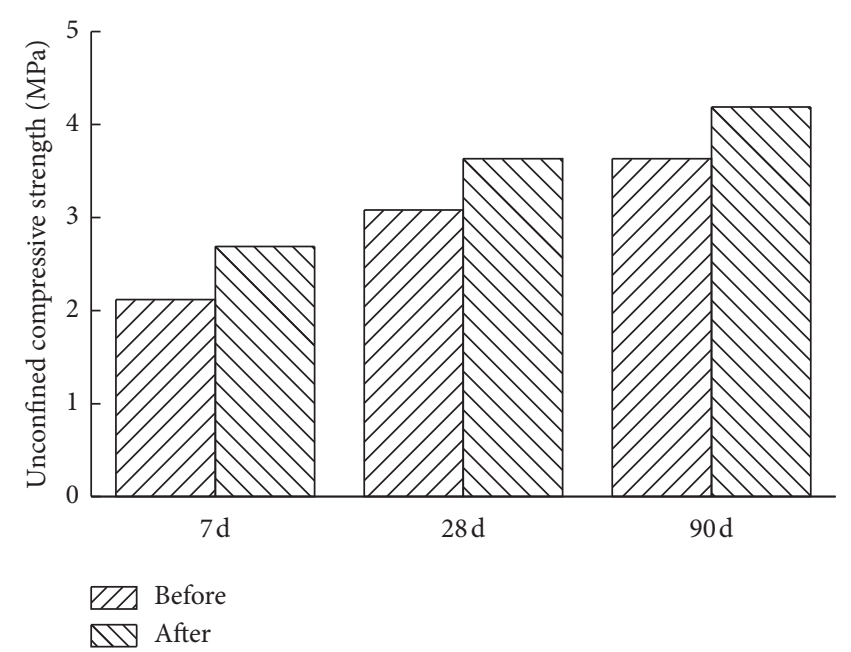

(a)

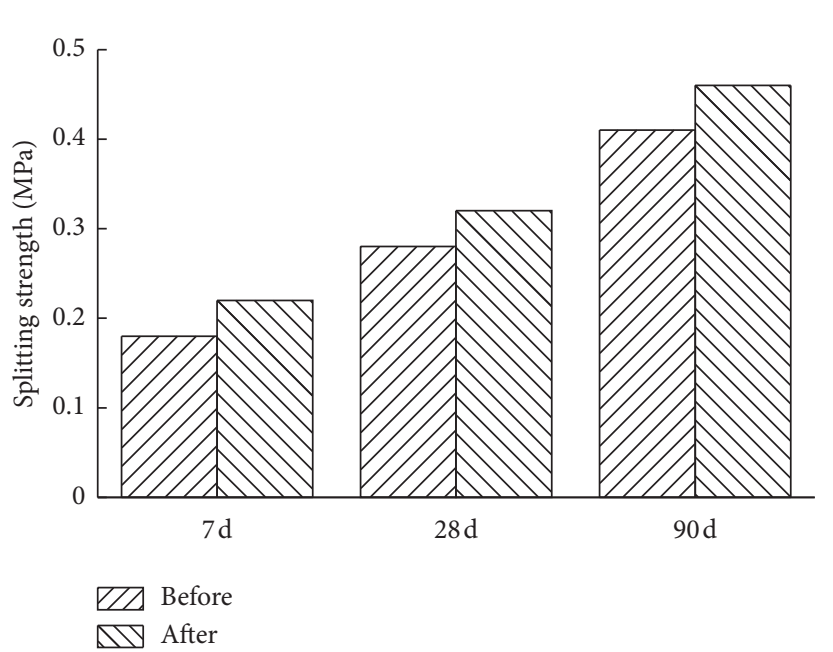

(b)

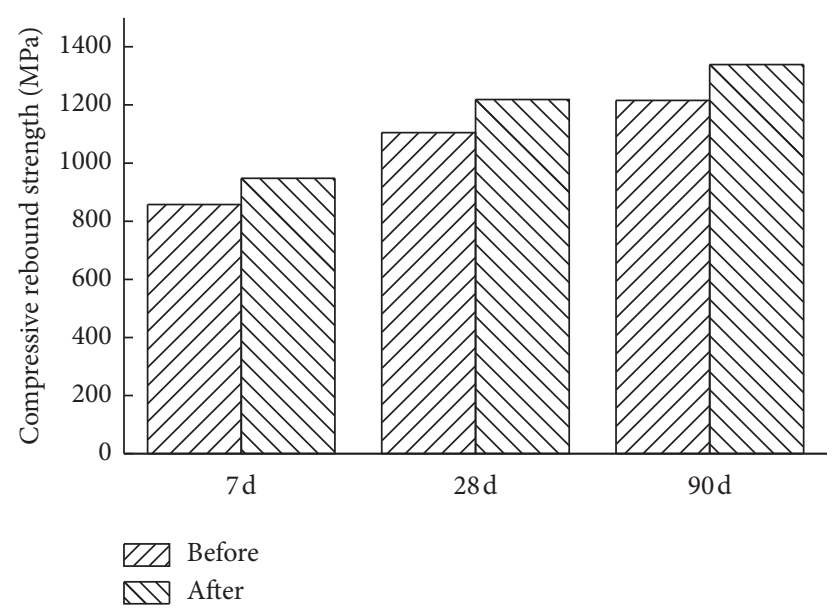

(c)

FIGURE 16: Mechanical performance results under 75\% of RCA content. (a) Unconfined compressive strength. (b) Splitting strength. (c) Compressive rebound modulus.

unconfined compressive strength and splitting strength. These two mechanical performance indexes increase by more than $20 \%$. The $7 \mathrm{~d}$ unconfined strength has also met the requirements of the subbase for second-class highway subjected to heavy traffic in China specification "Highway Asphalt Pavement Design Criterion" [52].

\section{Conclusions}

As a promising material in the pavement base, RCA play an increasingly significant role in the consumption of $C \& D$ waste and promoting sustainability of the construction industry. In this study, laboratory experiments were carried out to study the effect of different strengthening methods on RCA and mechanical properties of CSRM. The following conclusions can be summarized from the previous findings and observation:

(1) Compared with natural aggregates, the RCA has a higher water absorption rate, a smaller apparent density, and a larger crushing value. Especially for recycled brick aggregate, its water absorption rate is dozens of times of natural aggregate.

(2) Comparing the water absorption rate and crushing value before and after strengthening, the best strengthening way is obtained among different working conditions of the three strengthening methods. The sodium silicate solution is the best method in a strengthening concentration of $8 \%$ and strengthening duration of five hours.

(3) When the cement dosage is $4 \%$, with the increase of the RCA content, the unconfined compressive strength, splitting strength, and compressive rebound modulus of the CSRM firstly increase and then decrease. When the RCA content is $25 \%$, the mechanical properties of CSRM are the best. It can meet the strength requirements of the base and subbase layer of highway and first-class expressway. When the cement dosage is $5 \%$, all these mechanical 
properties all show a decreasing trend when the RCA content increases.

(4) Strengthening treatment was carried out for CSRM at $4 \%$ of the cement dosage. When it comes to $50 \%$ and $75 \%$ RCA content, the mixture does not meet the requirements of the specifications. By comparing the value of the three mechanical properties before and after strengthening, it was found that the strength growth rate of the 75\% CSRM after strengthening is significantly higher than that of $50 \%$. After strengthening treatment, the strength of CSRM with $50 \%$ RCA content has met the strength requirements of the base and subbase layer of highway and firstclass expressway. The $75 \%$ of RCA content can meet the strength requirements of the subbase of secondclass highways or inferior highways.

\section{Data Availability}

The data used to support the findings of this study are included within the article.

\section{Conflicts of Interest}

The authors declare that there are no conflicts of interest regarding the publication of this paper.

\section{Acknowledgments}

The authors gratefully acknowledge the National Natural Science Foundation of China (51878078, 51911530215, and 51478054), the Training Program for High-level Technical Personnel in Transportation Industry (2018-025), the Excellent Youth Foundation of Natural Science Foundation of Hunan Province (2018JJ1026), and the Key Project of Education Department of Hunan Province (17A008). This work was also supported by the Key Project of Open Research Fund of National Engineering Laboratory of Highway Maintenance Technology (kfj150103) and the Graduate Research Innovation Project of Hunan Province (CX20190644).

\section{References}

[1] H. Yang, J. Xia, J. R. Thompson, and R. J. Flower, "Urban construction and demolition waste and landfill failure in shenzhen, China," Waste Management, vol. 63, pp. 393-396, 2017.

[2] C. Sangiorgi, C. Lantieri, and G. Dondi, "Construction and demolition waste recycling: an application for road construction," International Journal of Pavement Engineering, vol. 16, no. 6, pp. 530-537, 2015.

[3] I. D. Rey, J. Ayuso, A. Barbudo, A. P. Galvin, F. Agrela, and J. De Brito, "Feasibility study of cement-treated $0-8 \mathrm{~mm}$ recycled aggregates from construction and demolition waste as road base layer," Road Materials and Pavement Design, vol. 17, no. 3, pp. 678-692, 2016.

[4] J. Zhang, L. Ding, F. Li, and J. Peng, "Recycled aggregates from construction and demolition wastes as alternative filling materials for highway subgrades in China," Journal of Cleaner Production, vol. 255, p. 120223, 2020.
[5] J. Zhang, F. Gu, and Y. Zhang, "Use of building-related construction and demolition wastes in highway embankment: laboratory and field evaluations," Journal of Cleaner Production, vol. 230, pp. 1051-1060, 2019.

[6] E. Department, "Review on road engineering in China," Chinese Journal of Highway, vol. 3, no. 26, pp. 1-36, 2013, (in Chinese).

[7] M. U. Hossain, C. S. Poon, I. M. C. Lo, and J. C. P. Cheng, "Comparative environmental evaluation of aggregate production from recycled waste materials and virgin sources by lca," Resources, Conservation and Recycling, vol. 109, no. 109, pp. 67-77, 2016.

[8] N. Serres, S. Braymand, and F. Feugeas, "Environmental evaluation of concrete made from recycled concrete aggregate implementing life cycle assessment," Journal of Building Engineering, vol. 5, no. 5, pp. 24-33, 2016.

[9] M. Wijayasundara, R. H. Crawford, and P. Mendis, "Comparative assessment of embodied energy of recycled aggregate concrete," Journal of Cleaner Production, vol. 152, pp. 406419, 2017.

[10] L. Zeng, X. Yao, J. Zhang, Q.-F. Gao, J. Chen, and Y. Gui, "Ponded infiltration and spatial-temporal prediction of the water content of silty mudstone," Bulletin of Engineering Geology and the Environment, vol. 2020, 2020.

[11] T. Park, "Application of construction and building debris as base and subbase materials in rigid pavement," Journal of Transportation Engineering, vol. 129, no. 5, pp. 558-563, 2003.

[12] K. Sobhan and R. J. Krizek, "Resilient properties and fatigue damage in stabilized recycled aggregate base course material," Transportation Research Record, vol. 1611, no. 1611, pp. 28-37, 1998.

[13] V. W. Y. Tam, X. F. Gao, and C. M. Tam, "Microstructural analysis of recycled aggregate concrete produced from twostage mixing approach," Cement and Concrete Research, vol. 35, no. 6, pp. 1195-1203, 2005.

[14] A. Djerbi, "Effect of recycled coarse aggregate on the new interfacial transition zone concrete," Construction and Building Materials, vol. 190, pp. 1023-1033, 2018.

[15] A. Arulrajah, A. Mohammadinia, A. D'Amico, and S. Horpibulsuk, "Cement kiln dust and fly ash blends as an alternative binder for the stabilization of demolition aggregates," Construction and Building Materials, vol. 145, pp. 218-225, 2017.

[16] A. Arulrajah, A. Mohammadinia, A. D'Amico, and S. Horpibulsuk, "Effect of lime kiln dust as an alternative binder in the stabilization of construction and demolition materials," Construction and Building Materials, vol. 152, pp. 999-1007, 2017.

[17] H. K. A. Al-Bayati, P. K. Das, S. L. Tighe, and H. Baaj, "Evaluation of various treatment methods for enhancing the physical and morphological properties of coarse recycled concrete aggregate," Construction and Building Materials, vol. 112, no. 112, pp. 284-298, 2016.

[18] L. P. Singh, V. Bisht, M. S. Aswathy, L. Chaurasia, and S. Gupta, "Studies on performance enhancement of recycled aggregate by incorporating bio and nano materials," Construction and Building Materials, vol. 181, pp. 217-226, 2018.

[19] H. Zhang, T. Ji, H. Liu, and S. Su, "Modifying recycled aggregate concrete by aggregate surface treatment using sulphoaluminate cement and basalt powder," Construction and Building Materials, vol. 192, pp. 526-537, 2018.

[20] J. Qiu, D. Q. S. Tng, and E.-H. Yang, "Surface treatment of recycled concrete aggregates through microbial carbonate 
precipitation," Construction and Building Materials, vol. 57, pp. 144-150, 2014.

[21] D. J. Zhang Chao and J. Guo, "Use of scrap concrete materials in semi-rigid base-course," Journal of Chang'an University (Natural Science Edition), vol. 22, no. 5, pp. 1-4, 2002, (in Chinese).

[22] S. S. Sun Jiaying and H. Jiang, "Esearch and application of recycled concrete aggregate for cement stabilized gravel," Journal of Building Materials, vol. 11, no. 5, pp. 580-584, 2008, (in Chinese).

[23] K. Sobhan and R. J. Krizek, "Fatigue behavior of fiber-reinforced recycled aggregate base course," Journal of Materials in Civil Engineering, vol. 11, no. 2, pp. 124-130, 1999.

[24] T. Bennert, W. J. Papp, A. Maher, and N. Gucunski, "Utilization of construction and demolition debris under traffictype loading in base and subbase applications," Transportation Research Record: Journal of the Transportation Research Board, vol. 1714, no. 1, pp. 33-39, 2000.

[25] M. Arabani, F. Moghadas Nejad, and A. R. Azarhoosh, "Laboratory evaluation of recycled waste concrete into asphalt mixtures," International Journal of Pavement Engineering, vol. 14, no. 6, pp. 531-539, 2013.

[26] I. Pérez, A. R. Pasandín, and L. Medina, "Hot mix asphalt using C\&D waste as coarse aggregates," Materials \& Design (1980-2015), vol. 36, pp. 840-846, 2012.

[27] M. Etxeberria, E. Vázquez, A. Marí, and M. Barra, "Influence of amount of recycled coarse aggregates and production process on properties of recycled aggregate concrete," Cement and Concrete Research, vol. 37, no. 5, pp. 735-742, 2007.

[28] K. Rahal, "Mechanical properties of concrete with recycled coarse aggregate," Building and Environment, vol. 42, no. 1, pp. 407-415, 2007.

[29] L. Butler, J. S. West, and S. L. Tighe, "The effect of recycled concrete aggregate properties on the bond strength between rca concrete and steel reinforcement," Cement and Concrete Research, vol. 41, no. 10, pp. 1037-1049, 2011.

[30] J. Mills-Beale and Z. You, "The mechanical properties of asphalt mixtures with recycled concrete aggregates," Construction and Building Materials, vol. 24, no. 3, pp. 230-235, 2010.

[31] C. S. Poon and D. Chan, "Feasible use of recycled concrete aggregates and crushed clay brick as unbound road sub-base," Construction and Building Materials, vol. 20, no. 8, pp. 578585, 2006.

[32] A. M. Azam and D. A. Cameron, "Geotechnical properties of blends of recycled clay masonry and recycled concrete aggregates in unbound pavement construction," Journal of Materials in Civil Engineering, vol. 25, no. 6, pp. 788-798, 2013.

[33] J. Zhang, J. Peng, L. Zeng, J. Li, and F. Li, "Rapid estimation of resilient modulus of subgrade soils using performance-related soil properties," International Journal of Pavement Engineering, vol. 2019, Article ID 1643022, 8 pages, 2019.

[34] J. Zhang, J. Peng, W. Liu, and W. Lu, "Predicting resilient modulus of fine-grained subgrade soils considering relative compaction and matric suction," Road Materials and Pavement Design, vol. 2019, Article ID 1651756, 13 pages, 2019.

[35] J. Li, Y. Pei, P. Xu, and H. Chang, "Determination of gradation of recycled mixed coarse aggregates for pavement base or subbase by crushing fractals," Advances in Materials Science and Engineering, vol. 2019, Article ID 7963261, 11 pages, 2019.

[36] GB175-2017, General Portland Cement, China Planning Press, Beijing, China, (in Chinese), 2017.
[37] J. Yang, Q. Du, and Y. Bao, "Concrete with recycled concrete aggregate and crushed clay bricks," Construction and Building Materials, vol. 25, no. 4, pp. 1935-1945, 2011.

[38] P. B. Cachim, "Mechanical properties of brick aggregate concrete," Construction and Building Materials, vol. 23, no. 3, pp. 1292-1297, 2009.

[39] JTG. E42-2005, Highway Engineering Aggregate Test Regulations, China Communications Press, Beijing, China, (in Chinese), 2005.

[40] JTG. F20-2015, Technical Rules for Construction of Road Pavement Base Courses, China Communications Press, Beijing, China, (in Chinese), 2017.

[41] H. Zhao, "Reinforcement and microstructure analysis of building solid waste recycled aggregate used in cement stabilized recycled mixture base," Master, Changsha University of Science \& Technology, Changsha, China, 2019.

[42] L. Festugato, E. Menger, F. Benezra, E. A. Kipper, and N. C. Consoli, "Fibre-reinforced cemented soils compressive and tensile strength assessment as a function of filament length," Geotextiles and Geomembranes, vol. 45, no. 1, pp. 77-82, 2017.

[43] A. Shayan and A. Xu, "Performance and properties of structural concrete made with recycled concrete aggregate," Aci Materials Journal, vol. 100, no. 5, pp. 371-380, 2003.

[44] J. J. Chen, J. J. Thomas, and H. M. Jennings, "Decalcification shrinkage of cement paste," Cement and Concrete Research, vol. 36, no. 5, pp. 801-809, 2006.

[45] F. El-Tantawy and Y. K. Sung, "A novel ultrasonic transducer backing from porous epoxy resin-titanium-silane coupling agent and plasticizer composites," Materials Letters, vol. 58, no. 1-2, pp. 154-158, 2004.

[46] T. P. Selvin, J. Kuruvilla, and T. Sabu, "Mechanical properties of titanium dioxide-filled polystyrene microcomposites," Materials Letters, vol. 58, no. 3-4, pp. 281-289, 2004.

[47] A. W. C. E. A. Okkonen, "Improvements to hydroxymethylated resorcinol coupling agent for durable bonding to wood," Forest Products Journal, vol. 53, no. 4, pp. 81-84, 2003.

[48] S. J. Monte and G. Sugerman, "Processing of composites with titanate coupling agents?a review," Polymer Engineering and Science, vol. 24, no. 18, pp. 1369-1382, 1984.

[49] J. Lu, P. Askeland, and L. T. Drzal, "Surface modification of microfibrillated cellulose for epoxy composite applications," Polymer, vol. 49, no. 5, pp. 1285-1296, 2008.

[50] JTG E51-2009, Test Regulations for Inorganic Binder Stabilization Materials for Highway Engineering, China Communications Press, Beijing, China, (in Chinese), 2009.

[51] A. Arulrajah, A. Mohammadinia, I. Phummiphan, S. Horpibulsuk, and W. Samingthong, "Stabilization of recycled demolition aggregates by geopolymers comprising calcium carbide residue, fly ash and slag precursors," Construction and Building Materials, vol. 114, pp. 864-873, 2016.

[52] JTG. D50-2017, Highway Asphalt Pavement Design Criterion, China Communications Press, Beijing, China, (in Chinese), 2017. 